\title{
KNOWLEDGE OF SOCIO-DEMOGRAPHIC FACTORS INFLUENCING HEALTH SERVICE USAGE AMONG PREGNANT MOTHERS IN NIGERIA
}

\author{
Dominic Azuh ${ }^{1 *}$, Akunna Azuh $^{2}$, Fagbeminiyi Fasina ${ }^{3}$, Paul Adekola $^{4}$, Emmanuel \\ Amoo $^{5}$, Muyiwa Oladosun 6 \\ ${ }^{1}$ Dr., Covenant University Ota, The Nigeria, dominic.azuh@covenantuniversity.edu.ng \\ ${ }^{2}$ Mrs., Covenant University Ota, The Nigeria, akunna.azuh@covenantuniversity.edu.ng \\ ${ }^{3} \mathrm{Dr}$., Covenant University Ota, The Nigeria, fagbminiyi.fasinai@covenantuniversity.edu.ng \\ ${ }^{4}$ Mr., Covenant University Ota, The Nigeria, paul.adekola@covenantuniversity.edu.ng \\ ${ }^{5}$ Dr., Covenant University Ota, The Nigeria, emmanuel.amoo@covenantuniversity.edu.ng \\ ${ }^{6}$ Dr., Covenant University Ota, The Nigeria, muyiwa.oladosun@covenantuniversity.edu.ng \\ ${ }^{*}$ corresponding author
}

\begin{abstract}
Poor knowledge of socio-demographic factors limit access and utilization of health care services among pregnant women. The objectives of this paper are to examine the factors which influence health care usage and to suggest policy guidelines to boost the use of healthcare particularly among antenatal women. The study covers five (5) rural political wards of Ado-Odo/Ota Local Government Area in Ogun State, Nigeria. A stratified sampling technique was adopted in selecting the respondents who were ever married women in child bearing age (15-49) years who had at least one live-birth in the last three years preceding the survey. Stratified sampling technique was employed because the study was based on different political wards. It enabled more consistent responses within each political ward. This technique consists in taking random samples within each selected ward and combining it with samples proportionate to the size of each ward to ensure representative of the population for wider generalization of findings. On the whole, 260 female respondents were randomly selected from five wards out of the sixteen wards. Data were gathered through questionnaire instrument and analyzed statistically using statistical package for social sciences. Regression analysis showed that treatment decision and distance to health facility are negatively related to health program usage by pregnant mothers. Educational attainments, payment of treatment bills, respondent's age and husband's perception about pregnancy are positively associated to antennal care (ANC) use. Also, since the F- statistics calculated is greater than the F- tabulated thereby validating the hypothesis that the sociodemographic characteristics of the respondents are significantly related to the health program usage by pregnant mothers. The above findings show that education, husband's perception about pregnancy, treatment decision and payment of treatment cost weigh more on the use of modern health care services. Hence, Costs alleviation for women seeking antenatal care and delivery services should be put in place to encourage women to use health services and government should give priority to women education and empowerment. In addition, effort should be made to revitalize rural health facilities and establish mid-way service delivery points to reduce the problem of distance.
\end{abstract}

Keywords: Knowledge, maternal mortality, usage, socio-demographic factors, antenatal care 


\section{INTRODUCTION}

Maternal health means ensuring that all women receive the care they need to be safe and healthy throughout pregnancy and childbirth. Women's health is a critical area, which reflects national health standards and basic to women's advancement. Maternal mortality and morbidity are critical priority problems that demand recognition and acceptance by the policy makers and health administrators. When women are in a state of pregnancy, their health status is far more complicated. It is no gainsaying that inappropriate, incorrect treatment or even lack of appropriate and timely interventions underlies most maternal deaths in developing countries and Nigeria in particular. It has been estimated that more than half a million women (many of them living in developing countries) die during pregnancy or childbirth or within a few weeks of delivery.(WHO 2013).

Despite the global effort to improve maternal health and safer delivery through the International Safe Motherhood Initiative, 1987 in Kenya, International Conference on Population and Development 1994, Beijing- Fourth world Conference on Women, 1995, United Nations SDGs 2015, and its local equivalent in Nigeria such as National Safe Motherhood Conference, Abuja 1990 among others there is still high maternal deaths in the country. Many studies have attributed this challenge to the state of health of pregnant women, poor delivery process, and poor antenatal and postnatal care utilization of available health care services (Elo, 1992, WHO, 2001, Abdoulaye Diallo 2006). The picture is really gloomy as NDHS 2013 revealed that only $36 \%$ of births were delivered in a health facility and $38 \%$ were attended to by a skilled birth assistant (NPC 2014). In spite of the low maternal reduction in Nigeria during the past 2 decades little is known about the current magnitude of use and socio-demographic factors determining the utilization of these services in Nigeria. Hence, this study becomes imperative to uncover the state of health care utilization among mothers during pregnancy and child delivery using community-based empirical data in order to affect sound policy intervention measures.

Furtherance to the above low knowledge of factors militating against the use of health services by mothers, socio-demographic factors have been the least focused in terms of research. The objectives of this paper are to examine major socio-demographic factors challenging maternal access to health care services during pregnancy and childbirth and proffer intervention strategies for improving the current low utilization of health care facilities by pregnant mothers.

\section{REVIEW OF RELATED LITERATURE}

Based on UNICEF (2005) data, the average lifetime risk of a woman in least developed country dying from complications related to pregnancy or childbirth is more than 300 times greater than for a woman living in an industrialized country. Millions of women who survive childbirth suffer from pregnancy related injuries, infections, diseases and disabilities, often with lifelong consequences. It further asserted from research that approximately 80 per cent of maternal deaths could be averted if women had access to essential maternity and basic health-care services which are far better in developed than in developing countries. Literature search reveals that modern use of health facility is low in developing countries, including Nigeria. The poor usage of health care services can be influenced by several factors ranging from social, economic, cultural, availability and accessibility. According to Federal Ministry of Health Nigeria (FMOH) $(2007 ; 2003)$, these factors work through the pervading high level of poverty in the country, low status of women and high prevalence of harmful traditional practices, all add up to pose great obstacles, to women's access to much needed reproductive health information and services. Maternal education has been found to relate positively with the utilization of maternal care services (Addai 2000; Celik and Hotchkiss 2000). Education serves as a crucial proxy for information, cognitive skills, and values; education exerts effect on health-seeking behavior through a number of pathways. These pathways include higher level of health awareness and greater knowledge of available health services among educated women, improved ability of educated women to afford the cost of medical health care, and their enhanced level of autonomy that results in improved ability and freedom to make health-related decisions, including choice of maternal services to use. Educated mothers are more likely to take advantage of public health care services than other women. Education may also impart feelings of self-worth and confidence as well as reduce the power differential between service providers and clients, thereby reducing the reluctance to seek care. (Elo 1992; Caldwell 1979). Cultural factors also affect the utilization of maternity care services in Africa (Leslie and Gupta 1989). In consonance with the above assertion, WHO (1998) corroborates that in many parts of Africa, women's decision making power is extremely limited, particularly in matters of reproduction and sexuality. The low status of women and husband's domination, all worsen the ugly and poor utilization of health care services. The tragedy of maternal mortality and the poor health status of women in Nigeria are deplorable. According to Federal Ministry of Health (2007) maternal mortality ratio in Nigeria is estimated to be 800 per 100,000 live births and that Nigeria contributes about $10 \%$ of the world's global burden of maternal mortality. 
In furtherance to the health situation in Nigeria, Jemisenia et al (2017) revealed that education, occupation and income impact on women's decision, quality of treatment, frequency of visits to the hospital, length and duration of hospital stay, time of visits to the hospital, and the type of health facilities visited to be among the factors influencing women's healthcare utilization. Studies like Azuh, Fayomi and Ajayi (2015); Bredensen (2013) and Halle-Ekane, et al. (2014) have found that women's level of education has a significant effect on their health care utilization, in spite of reservation from other scholars (Ochako, Fotso, Ikamari, and Khasakhala (2011). According to Eze and Adhure (2014) education, income and other socio-cultural factors influence health care services among women. In a Community based cross-sectional survey, Andemariyam et al (2017) found out during interview that residency, marital status, educational status of the women, levels of education attended, monthly income, family size, husband occupation, distance of health institution and obstetric factors have statistically significant association with institutional delivery. Nai-Peng Tey and Siow-li Lai (2013) found from the Demographic and Health Surveys data conducted in Bangladesh, India, Pakistan, Kenya, Nigeria, and Tanzania that within each country, the poorer, less educated and rural women had higher unmet need for maternal care services. While Okutu (2011) argue that younger (aged less than 20years) and middle aged mothers (aged 20-34years) are more likely to seek pregnancy-related care services from skilled attendants compared to mothers aged 34 and above years in Uganda; Ishmael et al (2014) found positive association between a woman's educational attainment and visit to antenatal care clinic, place of delivery and tetanus toxoid injection. In consonance with the above findings, Vickita A.A Harvey (2014) observed that age, sex, social status, marital status, education, ethnicity, religion, and family size, employment, and type of occupation were statistically significant in determining health care service utilization in Ghana. Other studies (Azuh et al 2017, 2014; Coimbra et al. 2007; Owens 2008) have maintained that the quality and the levels of women's health care utilization is largely dependent on their socio-economic factors and other socio-cultural factors.

\section{METHODOLOGY}

The study covers five (5) rural wards of Ado-Odo/Ota Local Government Area in Ogun State, Nigeria. The study used face-to-face structured interview and focus group discussion. A stratified sampling technique was adopted in selecting the respondents who were ever married women in child bearing age (15-49) years who had at least one live-birth in the last two years preceding the survey. On the whole, 260 female respondents were randomly selected from five political wards out of the sixteen wards in the local government area. The sample size of 260 was determined by using Taro Yamane formula. The survey data were analyzed statistically using statistical package for social sciences (SPSS).

\section{RESULTS AND DISCUSSIONS}

Table 1 shows that the educational attainment of the respondents is very poor with slightly above half of the population having only secondary education (55.5\%). Respondents with no schooling, those having primary level account for 22.7 and 18.2 per cent respectively. Nevertheless, a negligible number of the respondents had attained above secondary level education (3.6\%). This is serious in view of the importance of education as a vital force in shaping the whole gamut of an individual's life particularly mother's empowerment.

The occupational status indicates that larger proportion of the respondents is into trading $(37.7 \%)$. This is followed by unskilled/laborers (23.2\%), farming (15.5\%) and artisans (14.5\%). On the other hand, mothers who are fulltime housewives account for the least $(9.1 \%)$. Similarly, the husband's occupational status indicates that larger proportion of the respondent's husbands is into unskilled jobs $(30 \%)$. This is followed by trading (27.7\%), artisans (18.8\%) and farming (12.7\%). Nevertheless, 10 per cent of husbands are unemployed. The question on the age of the respondents at the time of survey shows that 15-19 years registered $15 \%$, followed by $20-29$ with $55 \%, 30-34$ category accounts for $20 \%$ and the last category 35 years and above accounts for the least proportion (10\%). It is observed that low age at marriage exist in the study population, as large proportion of them $(70 \%)$ married in their 20 s.

Distance to the health facility is also a major retarding factor in accessing health services among the five political wards in the study area. While $68 \%$ of the respondents have health facility within two kilometers distance from their homes, a reasonable proportion (32\%) of these respondents has to walk beyond three kilometers distance to access health services. This is a problem, especially as the road network is poor or virtually not in existence and lack of transportation. A pregnant mother will prefer to visit the next door traditional birth attendant rather than to walk for kilometers to the health center where she has no confidence in the service. The low status of women is manifested on who decides where the household including pregnant mother should go for treatment as well as the payment of the treatment costs. These are exclusively the husband's responsibility especially in African countries where culturally, male dominance and women subjugation are normal ways of life. In the study area, 73 per cent of the respondents stated that it is 
their husbands who decide when and where to go for treatment and equally pay for the treatment costs. The implication of this is that a woman has no reproductive right whether pregnant or not. She is grossly incapacitated to take care of herself as permission is needed for any visit to health clinic.

The awareness of place of antenatal care (ANC) is fascinating as overwhelming proportion of the respondents admitted knowledge of place of ANC treatment (93\%). However, the common reasons hindering attendance or registration for antenatal care is high cost of ANC service. Only one-tenth (10.5\%) of the respondents agreed that what they spend at health centers is convenient (cheap) for them. However, 51.8 per cent and 37.7 per cent stated moderate and expensive charges respectively. Cost may reduce women's use of maternal health services from having hospital -based deliveries or seeking care even when complications arise. The assistants during pregnancy and child birth were identified to be nurses/midwives (56.8\%), doctors (20\%); and traditional birth attendants (17.7\%) and relatives (5.5\%). The worrisome aspect of this is the high proportion of mothers patronizing home delivery at the hands of these non-medical personnel in Nigeria and other developing countries.

It is equally interesting to note that while over half of the respondents $(55 \%)$ patronize non-modern facility, slightly above three-fifths of them stated that their husbands do not perceive pregnancy as risky journey. This relates to the causal treatment given to pregnant women in the study area.

Table 1 Socio-demographic and Health characteristics of respondents

\begin{tabular}{|c|c|c|c|c|c|}
\hline Variable & No $\mathrm{N}=\mathbf{2 6 0}$ & Percent & Variable & No $\mathrm{N}=\mathbf{2 6 0}$ & Percent \\
\hline $\begin{array}{l}\text { Educational } \\
\text { Attainment }\end{array}$ & & & Occupational Status & & \\
\hline None & 59 & 22.7 & Farming & 40 & 15.5 \\
\hline Primary & 47 & 18.2 & Housewife & 24 & 9.1 \\
\hline Secondary & 144 & 55.5 & Unskilled/Laborer & 60 & 23.2 \\
\hline Tertiary & 10 & 3.6 & Artisans & 38 & 14.5 \\
\hline 55 and above & 45 & 12.5 & Trading & 98 & 37.7 \\
\hline Age(Years) & & & $\begin{array}{l}\text { Distance to health } \\
\text { facility }\end{array}$ & & \\
\hline $15-19$ & 46 & 17.7 & $<1 \mathrm{~km}$ & 122 & 46.8 \\
\hline $20-29$ & 145 & 55.8 & $1-2 \mathrm{~km}$ & 54 & 20.9 \\
\hline $30-34$ & 45 & 17.3 & $3-4 \mathrm{~km}$ & 24 & 9.1 \\
\hline 35 and above & 24 & 9.2 & $5 \mathrm{~km}$ and above & 60 & 23.2 \\
\hline Treatment Decision & & & $\begin{array}{l}\text { Knowledge of antenatal } \\
\text { care (ANC)Treatment }\end{array}$ & & \\
\hline Husband & 189 & 72.7 & Yes & 241 & 92.7 \\
\hline Wife & 43 & 16.4 & No & 19 & 7.3 \\
\hline
\end{tabular}


IJASOS- International E-Journal of Advances in Social Sciences, Vol. III, Issue 9, December 2017

\begin{tabular}{|c|c|c|c|c|c|}
\hline Relatives & 28 & 10.9 & & & \\
\hline $\begin{array}{l}\text { Perception of ANC } \\
\text { Cost }\end{array}$ & & & $\begin{array}{l}\text { Assistance during } \\
\text { Delivery }\end{array}$ & & \\
\hline Very Expensive & 5 & 1.8 & & & \\
\hline Expensive & 93 & 35.9 & Doctors & 52 & 20.0 \\
\hline Moderate & 135 & 51.8 & Nurses/Midwives & 148 & 56.8 \\
\hline Cheap & 27 & 10.5 & $\begin{array}{l}\text { Traditional Birth } \\
\text { Attendants }\end{array}$ & 46 & 17.7 \\
\hline & & & Relatives & 14 & 5.5 \\
\hline Preferred Health Facility & & & $\begin{array}{l}\text { Husband's Perception } \\
\text { about Pregnancy }\end{array}$ & & \\
\hline Hospital/PHC & 117 & 45 & Risky & 101 & 39 \\
\hline $\begin{array}{l}\text { Traditional Healer's } \\
\text { Home }\end{array}$ & 81 & 31 & Non-risky & 138 & 53 \\
\hline Faith Clinic & 39 & 15 & Indifference & 21 & 8 \\
\hline Indifference & 23 & 9 & & & \\
\hline
\end{tabular}

Source: Field Survey/Authors' Computation 2017

Regression analysis (Table 2) shows that treatment decision and distance to health facility are negatively related to health program usage by pregnant mothers in the study area. Educational attainments, payment of treatment bills, respondent's age, husband's perception about pregnancy and perception of ANC cost are positively associated to ANC use. This implies that the higher the level of mothers' education, the more likely it is that they will use health facility or attend ANC counseling. Nevertheless, all variables are significantly related to the preferred health facility. This result implies that variables relating to husband such as perception about cost of service, treatment decision and payment of treatment cost weigh more on the use of modern health care services. Furthermore, since the F- statistics calculated is greater than the F-tabulated the hypothesis that the socio-demographic characteristics of the respondents are significantly related to the health program usage by pregnant mothers is upheld.

The policy implications of findings and recommendations of the current study are very insightful towards stemming the ugly health situation in Nigeria. The Nigeria's adverse health indicators is caused by several factors which hinder the utilization by expectant mothers leading to doubt in the achievement of Sustainable Development Goals especially health related goals. These factors retard the preference of people towards health care system. The important factors hindering patronage of health facility according to the present study are educational attainment, perception of antenatal care cost, proximity to health facility, who pays the treatment bills and respondent's age among other inhibiting factors. Hence, government should direct intervention programs with emphasis on these key areas for improving delivery of health care services more so to pregnant women and children in rural areas. 
Table 2 Regression Analysis Coefficients

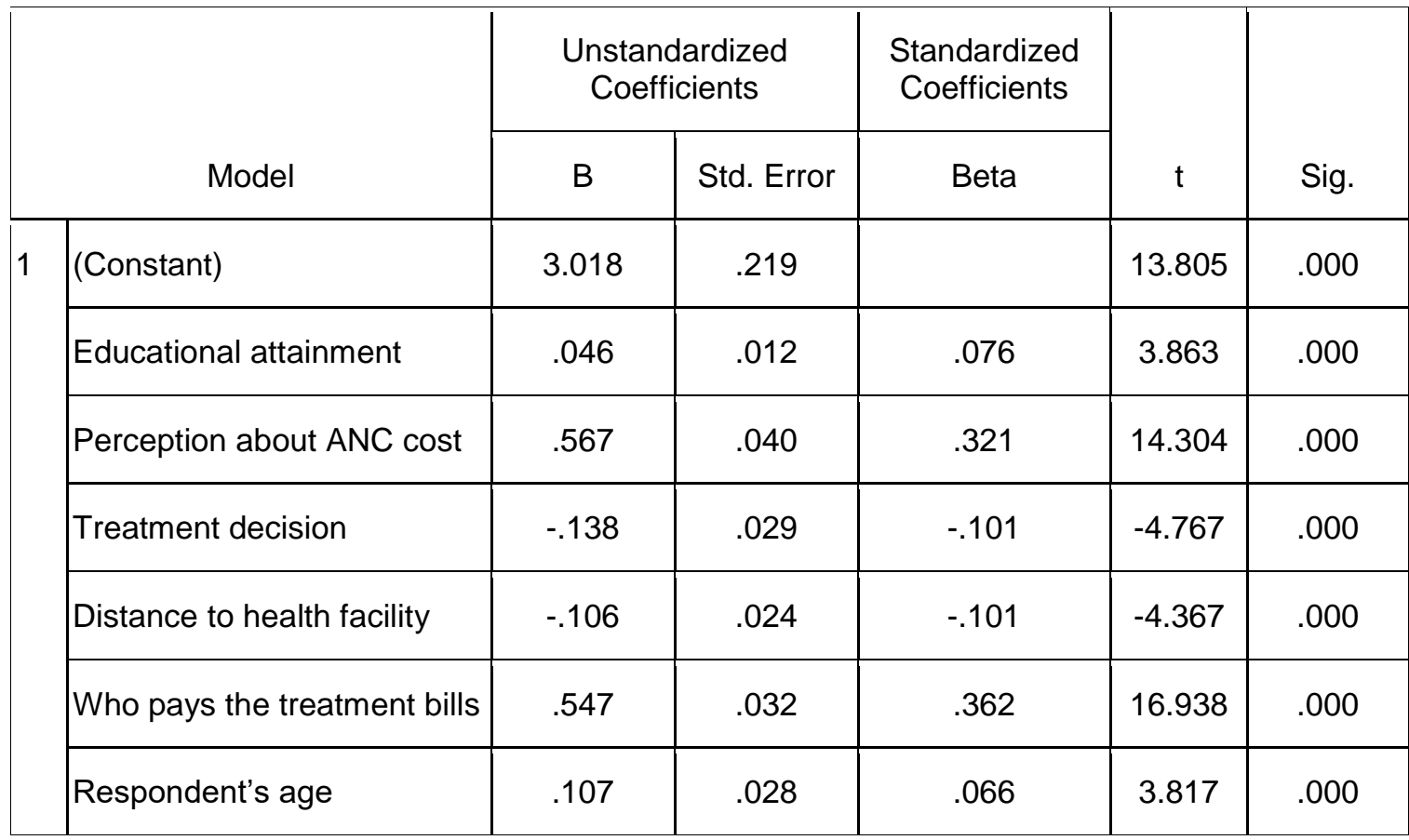

R Square +.982; Adjusted R Square = .980; F = 477.614

Dependent Variable: Preferred health facility

\section{CONCLUSION}

Maternal mortality in developing countries continues to be a serious public health problem and contributes to the low life expectancy in Nigeria. The study has identified several factors that have important influence on utilization of maternal health services in the study area. Among these include the predictor variables such as education and occupation of mothers, distance to the health facility among others. Hence, the study recommends costs alleviation for women seeking antenatal care and delivery services to encourage them to use health services and government should give priority to women education and empowerment. In addition, effort should be made by government to revitalize rural health facilities and establish mid-way service delivery points to reduce the problem of distance.

\section{ACKNOWLEDGEMENTS}

The authors wish to thank the respondents for participating in the study. Also we appreciate Covenant University for supporting this study.

\section{REFERENCE LIST}

Abdoulaye, Diallo (2006). Maternal mortality in Africa. The Internet Journal of Health, vol. 5(1).

Addai, I. (2000). Determinants of use of maternal-child health services in rural Ghana. Journal of Biosocial Science, 32 (1).

Andemariyam Yohannes Moges, Tamene Naba Yaya. Determinants of Safe Delivery Service Utilization among Women of Childbearing Age in Egela Sub-Woreda, Tigray, Northern Ethiopia. Science Journal of 
Public Health. Vol. 5, No. 6, 2017, pp. 411-418.

Azuh, D. E., Azuh, A. E., Iweala, E. J., Adeloye, D., Akanbi, M., \& Mordi, R. C. (2017).. Factors influencing maternal mortality among rural communities in southwestern Nigeria. International Journal of Women's Health, 9, 179-188.

Azuh, D., Fayomi, O., \& Ajayi, L. (2015). Socio-cultural factors of gender roles in women's health care utilization in Southwest Nigeria, Open Journal of Social Sciences, Vol. 3, 105-117.

Azuh, D., Nwaubani, O. O. and Ugwuanyi, B. E. (2014). Socio-demographic Determinants of Health Care Program Usage by Women during Pregnancy and Child-birth in Ado-Odo/Ota Local Government Area of Ogun State, Nigeria. International Journal of Scientific Research. Vol. 3(6), 16-21.

Bredensen, J. A. (2013). Women's use of healthcare services and their perspective on healthcare utilization during pregnancy and childbirth in a small village in Northern India, American International Journal of Contemporary Research, Vol. 3(6), 1-9.

Caldwell, J (1979). Education as a Factor in Mortality Decline: An Examination of Nigerian Data. Population Studies 33.

Celik, Y. and Hotchkiss, D. R. (2000). The Socioeconomic determinants of Maternal Health Care Utilization in Turkey. Social Science and Medicine, 509 (12).

Coimbra, L. C., Figueredo, F. P., Silva, A. A. M., Barbien, M. A., Bettoil, H. Caldas, A. J. M., Mochel, E. G., \& Ribero, V. S. (2007). Inadequate utilization of prenatal care in two Brazilian birth cohorts, Braz J Med Boil Res, Vol. 40(9), 1195-1202.

Elo, T. Irma (1992). Utilization of Maternal Health -care Services in Peru: The R of Women's Education. Health Transition Review, vol 2 (1).

Eze, B. U., \& Adhure, H. (2014). Hindrances to effective usage of family planning methods among women in Adankolo Lokoja urban area of Kogi State, International Journal of Current Research and Academic Review, Vol. 2(10), 182-190.

Federal Ministry of Health (2007). Integrated Maternal, Newborn and Child Health Strategy. Abuja: FMOH.

Federal Ministry of Health (2003). National Study on Essential Obstetric care Facilities in Nigeria. Abuja: $\mathrm{FMOH}$.

Halle-Ekane, G. E., Obinchemti, T. E., Nzang, J. L. N., Mokube, M. N., Njie, M. M., \&

Njamen, T. N. (2014). Assessment of the content and utilization of antenatal care services in a rural community in Cameroon: A cross sectional study, Open Journal of Obstetrics and Gynecology, Vol. 4, 846856.

Harvey, Vickita Akosua Antwiwaa, "Socio-economic and Cultural Determinants of Health Care Services Utilization in Ghana" (2014). UNLV Theses, Dissertations, Professional Papers, and Capstones. 2266.

Ishmael Kalule-Sabiti, Acheampong Yaw Amoateng and Mirriam Ngake (2014). The Effect of Sociodemographic Factors on the Utilization of Maternal Health Care Services in Uganda. African Population Studies, Vol. 28, No. 1. 515-525.

Jemisenia John Oluwaseyi, Ezenagu Nnedinma Roseline, Adejoh Arome (2017). Socio-Economic Status and Women's Healthcare Utilization: A Study of Selected Areas in Nigeria. Rom. Jour. of Sociological Studies, New Series, No. 1, p. 25-48.

Leslie, J. and Gupta, G.R (1989). Utilization of formal services for Maternal Nutrition and Health Care. Washington, D C: International Centre for Research on Women.

Nai-Peng Tey and Siow-li Lai (2013). Correlates of and Barriers to the Utilization of Health Services for Delivery in South Asia and Sub-Saharan Africa. The Scientific World Journal

Volume 2013, pp.1-11.

National Population Commission (2014) Nigeria Demographic and Health Survey 2013. Calverton, Maryland: National Population Commission and ORC/Macro.

Nigeria Federal Ministry of Health (2003). Technical Report on Study on Essential Obstetric care facilities in Nigeria. Abuja: FMOH. 
Ochako, R., Fotso, J.-C., Ikamari, L., \& Khasakhala, A. (2011). Utilisation of maternal health services among young women in Kenya: Insights from the Kenya Demographic and Health Survey, 2003, BMC Pregnancy \&Childbirth, 11.

Okutu, D. 2011. Access to and utilization of antenatal care services in Uganda. Uaps 2011. princeton.edu/papers/110707.

Owens, G. M. (2008). Gender differences in health care expenditure, resources utilization and quality care, $J$. Manag Care Pharm, Vol. 14(3), 2-6.

UNICEF (2005). The State of World's Children. New York: Oxford University Press.

World Health Organization (1998). Improved Access to Maternal Health Services. WHO 98 (7). Geneva: WHO.

WHO, UNICEF, UNFPA, World Bank and UN (2013). Trends in Maternal Mortality: 1990 to 2013 Estimates by World Health Organization, UNICEF, UNFPA, World Bank and UN. Executive Summary. Geneva: WHO.

World Health Organization (2001). Maternal mortality Estimates Geneva: Switzerland, World Health Organization. 